\title{
Transactive Memory System and QM: Exploring Knowledge capacities
}

\author{
Paper published in
}

Industrial Management \& Data Systems

Full citation to this publication:

Cabeza Puges, D.; Gutiérrez Gutierrez, L. and Lloréns Montes, F.J. (2013): "Transactive Memory System and QM: Exploring Knowledge capacities". Industrial Management \& Data Systems, Vol. 113, n.2, pp.294-318.

https://doi.org/10.1108/02635571311303587

Thank you for your interest in this publication. 


\title{
Transactive Memory System and QM: Exploring Knowledge Capacities
}

\author{
Cabeza Puges, D. \\ Gutierrez-Gutierrez, L. \\ Lloréns Montes, F.J. \\ University of Granada (Spain)
}

\begin{abstract}
Objective The goal of this paper is to study how transactive memory systems (TMS) facilitate the transfer and absorption of knowledge in the presence of Quality Management (QM) within a university research-development $(\mathrm{R} \& \mathrm{D})$ environment.
\end{abstract}

Design/methodology The data come from a simple random sampling of 257 Spanish university $R \& D$ groups in nine different areas of knowledge. To verify the hypotheses, we used multiple linear regression analysis with a moderating effect.

Conclusions The conclusions show that the relationship between knowledge transfer (KT) and TMS is significant when QM practices are included as a moderating variable but that this is not the case for knowledge absorption (KA), which does not show any effect.

Research limitations/implications The effects described were found in a sample composed of various R\&D sectors taken from a single country and not distributed equally. Further, the perception analyzed represents the judgment of a single manager.

Practical implications It is interesting to study this interaction in university R\&D because of the important role R\&D plays in the development of regions. Improving the internal processes 
of this research helps to make its results more competitive. Our study contributes information on non-business management and introduces university R\&D to the use of QM practices.

Originality/value We find no studies that test empirically the moderating effect of QM practices on the relationships studied in university $R \& D$. Our results contribute information to help fill this gap and demonstrate once again that QM practices can be applied to any environment.

Key words: TMS; QM; Knowledge transfer; Knowledge absorption; R\&D groups Type of article Research article

\section{Introduction}

The literature finds transactive memory systems (TMS) to be associated with work groups and teams. TMS are used to study the effectiveness of these groups' cognitive mechanisms. Wegner (1986) introduced this topic, which is considered to be a theory of group cognition that conceptualizes the processes of knowledge exchange and recovery in groups for shared use (Jackson, 2011).

Many studies have shown that TMS have positive effects on group performance (Moreland and Myaskovski, 2000). This effect has been studied in research laboratories (Hollingshead, 2001), samples of students (Lewis, 2004), and teams within a single organization (Austin, 2003).

It is increasingly popular in the literature to analyze TMS in different sectors, especially when the analysis is performed on small groups, due to the direct impact the construct has on them. The great importance of the construct lies in the fact that the individuals who compose the work group take responsibility for the different areas of knowledge that are of interest or utility to the group in general. Individual knowledge grows over time, leading to specialization. All members' knowledge is available to any member of the group (Jackson, 2011). 
Since the TMS is a little-studied construct, there are still gaps in our knowledge of it. For example, the relationship between TMS and the different capacities has not received much study. In addition, research on the elements that favour the creation of dynamic capabilities remains scattered, scarce, and insufficient. Our study attempts to contribute information to answer these questions, specifically by linking TMS to knowledge transfer (KT) and knowledge absorption (KA) as dynamic capacities and attempting to determine how TMS facilitate these capacities. Thanks to their shared memory, TMS can promote more efficient use of human resources, since they reduce the burden of cognitive development on each individual (Akgün et al., 2006).

We think that this relationship can be strengthened if we introduce QM practices as a moderating variable in the relationships. We decided to research this effect because much has been written recently on the positive and significant impact of QM on organizational performance (Silá and Ebrahimpour, 2005; Jiménez and Martínez, 2009). It is interesting to observe what happens in the relationship between TMS and the dynamic capacities of KT and KA when working in a QM environment.

We will focus our analysis specifically on groups that belong to university R\&D initiatives. We have chosen this sector because very few studies in the literature link QM to R\&D. This is a very young topic, and the most important studies have been developed by academics and researchers (Kumar and Boyle, 2001; Prajogo and Sohal, 2006; Prajogo and Hong, 2008). No research to date reports specifically on the university environment. Further, it is well known that, although QM is a construct that began in the business sector, it has spread to non-business organizations regardless of sector, yielding positive results in this respect.

The general goal of this study is to explain how TMS promote the capacities of KT and KA in the presence of QM practices. The literature shows no previous studies that analyze the relationships proposed. The studies that have appeared are oriented fundamentally to the 
pharmaceutical and manufacturing sectors. We thus affirm that analysis of the impact of QM on university R\&D has not been undertaken.

The article is structured as follows: After this introduction, we present a literature review of four basic areas. First, we tackle TMS, emphasizing their main characteristics. Second, we describe QM in R\&D. Third, we develop the connection between QM practices when they moderate the relationship of TMS to the dynamic capacities analyzed. Following the literature review, we describe the methodology and present the data analysis. Finally, we discuss the results and gather the main conclusions, limitations, and future lines of research.

\section{Literature review and development of the hypotheses}

\subsection{Conceptualizing TMS: main characteristics}

TMS are defined as the work cooperation that occurs between the members of a team in order to learn, remember, and communicate knowledge relevant to the group and its different facets (Hollingshead, 2001). The word "transactive" implies that the development of the system requires a large quantity of interaction and observation (Alavi and Tiwana, 2002). TMS take into account three issues: specialization, which involves the capacity of the group's members to understand who possesses specialized knowledge; credibility, or the capacity to trust in the reliability of others' knowledge; and coordination, which is related to efficacy in the organization of the differentiated knowledge (Lewis, 2003).

TMS are more likely to develop in small and medium-sized teams than in large teams, due to the fact that the former provide more opportunities to discover the capacities of others (Sharma and Ghosh, 2007). Larger groups require technological support to imitate these processes, and their members are more scattered and dispersed (Sharma and Ghosh, 2007; Jackson, 2011). Whatever the group, improvement in the development of TMS and its functioning in some groups better than in others depends on the group's capacity to store and share information (Jackson, 2011). Many researchers have shown that TMS affect 
performance positively (Moreland and Myaskovski, 2000). They have been studied in research laboratories (Hollingshead, 2001), samples of students (Lewis, 2004), and teams within a single organization (Austin, 2003). The effect that the construct has on improving knowledge integration in the group is now recognized. Thanks to its shared memory, the group promotes more effective use of human resources and reduces the burden of cognitive development for each individual (Akgün et al., 2006), becoming a system of meta-knowledge responsible for ensuring and recovering important information.

\section{2 $Q M$ in $R \& D$}

QM is defined as a holistic management philosophy that has been adopted as an approach to improving the competitiveness of organizations (Prajogo and Hong, 2008). However, a definition that is more operational and in better agreement with the purposes of this study is one which states that quality management $(\mathrm{QM})$ is defined as a "set of mutually reinforcing principles, each of which is supported by a set of practices and techniques" (Dean and Bowen, 1994). As it is explained below, based on previous studies of R\&D (Prajogo and Sohal, 2006; Prajogo and Hong, 2008), our paper studies the following QM practices: leadership, strategic planning, customer focus, information and analysis, management of people and teamwork (See Appendix A for description).

The first study that attempted to apply the principles of QM to the R\&D process was performed by Price (1995) to improve products and communication in the sector. Subsequently, other research appeared, such as studies by Kiella and Golhar (1997) and Pearson et al. (1998), and more recently those by Prajogo and Sohal (2006) and Prajogo and Hong (2008). These studies analyze R\&D in firms as it is linked to the capacity to innovate. We ground our work specifically in these studies but use a framework outside that of the entrepreneurial sector, since we study university R\&D. 
We believe analysis of $\mathrm{QM}$ in university $\mathrm{R} \& \mathrm{D}$ to be innovative, since there are no studies in the literature that describe results in this sector, a sector traditionally considered to be hierarchical and to have an isolated work environment (Kiella and Golhar, 1997). Prajogo and Hong (2008) consider the implementation of QM in R\&D to be a challenge, when compared to other areas. We find no studies that explain what happens in university $R \& D$ when it is immersed in a QM environment, and our study attempts such an explanation. For this reason, we take the practices analyzed from the study by Prajogo and Sohal (2006) performed on R\&D groups that analyze coalignment between $\mathrm{QM}$ and $\mathrm{R} \& \mathrm{D}$ management. We have included teamwork (TW) because it recognizes the coordinated effort of the group as the most important factor (Grover et al., 2006).

\section{$2.3 T M S$ and $Q M$}

\subsubsection{Connection between QM practices when they moderate the relationship of} specialization, credibility, and coordination in TMS and KT within university $R \& D$

KT is defined as a dynamic capacity related to organizational learning that affects organizations' performance positively (Argote and Ingram, 2000). It is the process through which a unit, group, department, or division is affected by the experience of others (Argote and Ingram, 2000). Recent studies have linked KT to TMS (Huang, 2009; Jackson, 2011, Hamid et al., 2011). These studies also mention the scarcity of research that focuses explicitly on the role of TMS in enabling KT (Hamid et al., 2011).

Our research analyzes TMS, which we call a "facilitating element" linked to KT and moderated by the relationship with QM practices. We have analyzed the construct from two dimensions: first, specialization within the system (TMSS) and, second, credibility and coordination (TMSC).

The connection of TMS to KT, as seen from the two dimensions proposed and moderated by QM practices, should both be favourable and have a positive impact. Many authors recognize 
the advantages of working in a quality environment (Gutiérrez et al., 2010, Heras et al., 2011) because such an environment is beneficial for the generation of ideas in the group and improves the effectiveness of exchange. Applying these ideas in R\&D provides a way for these organizations to grow and to be competitive (Satyendra and Harsh, 2011). QM practices can moderate the relationships explained above, since they help team members to work in a coordinated and organized manner, based on teamwork and leadership practices. The better human resources are managed, the better the coordination and interaction achieved by the members (Faraj and Sproull, 2000). Leadership helps to reinforce the approach that the team is a distributed knowledge system (Yoo and Kanawattanachai, 2001) by activating specialization in the system.

QM helps R\&D to focus on the customer's needs and expectations (Chatterji and Davidson, 2001) and increases the effectiveness of the exchange through teamwork. Each member is responsible for specific knowledge, which, when coordinated with others' knowledge, constitutes complementary and mutually reinforcing knowledge stores (Huang, 2009). Human resources are responsible for making exchange of knowledge concrete, as they affect the success or failure of the procedure in many ways (Tarawneh and Ahmad, 2010). Thus, QM permits them to focus better on the objectives through the proper strategic planning, which is supported by information and analysis, stimulating KT.

\subsubsection{Connection of QM practices when they moderate the relationship of specialization and} credibility and coordination in the TMS to $K A$ within university $R \& D$

$\mathrm{KA}$ is defined as a dynamic capacity related to organizational learning that affects organizations' performance positively. It is a set of organizational routines and strategic processes through which knowledge is acquired, assimilated, transformed and applied with the goal of creating an organizational dynamic capacity (Zahra and George, 2002). The 
connection of TMS and their specificities to KA has received little study. The most important studies were performed by Akgün et al. (2006) and Jackson and Klobas (2008).

KA has received less study than knowledge transfer, and the explanation of how specialization, credibility, and coordination in TMS are related to KA has hardly been studied. Despite this absence of antecedents, we believe that QM practices moderate the relationship between the variables positively.

Husted and Michailova (2002) argue that people tend to resist using the knowledge they receive from others. Quality could be the technique used to attempt to improve on this issue, since QM as supported by its practices seeks to educate workers. For example, transformational leadership is leadership that seeks QM, and transformational leadership translates into management that promotes higher performance throughout the entire organization (Hirtz et al., 2007). Such a situation encourages the relationships proposed here, since they are developed in a climate in which the leaders are primarily managers and are responsible for management and leadership (Lakshman, 2006).

Ghosh et al. (2003) add that it is QM's process of strategic planning that determines the organization's positive results. Strategic planning is one of the most powerful tools at our disposal today for changing organizations' modes of analysis, projection, and management. Therefore, it is vital to create a climate that encourages knowledge absorption and the elements that facilitate it, since this strategy would be included within the organization's objectives. QM has gone beyond the concept of the marketing customer, introducing the concept of internal customer as a new way of understanding the production process and the relationships generated within the organization itself. From the perspective of this concept, KA finds the perfect means to develop this process dynamically and continuously. Information and analysis facilitate the creation of a common language in the organization (Antony, 2000), encouraging KA. 
The importance of teamwork to strengthen these relationships is undeniable. This QM practice improves the levels of human resource satisfaction (Boon et al., 2007) and encourages KA in groups, because it recognizes not only individual effort but also coordinated group effort, which becomes even more important (Grover et al., 2006).

In sum, the QM practices analyzed encourage the generation of ideas in the group, facilitate creativity, and improve efficacy and efficiency in the exchange of intellectual information and abilities.

We believe that TMS and QM practices encourage the transfer of specialized knowledge, because they facilitate the exchange and dissemination of knowledge in different areas (Akgün et al., 2006). We suggest that the presence of different areas of knowledge indicates specialization. Within TMS, knowledge is possessed by some member of the group. It is here that TMS act, facilitating specialized knowledge exchange and affecting KT positively. This effect on KT is intensified if the exchange is connected to QM practices, because TMS create distributed memory in which each member is responsible for certain knowledge, which, when coordinated with the other members of the group, is complemented and strengthened. Therefore, we propose the following hypothesis:

H1. QM practices moderate the effect of specialization in TMS as they relate to KT in R\&D groups.

The relationship between credibility and coordination in TMS and QM practices is clear, since these dimensions encourage knowledge transfer in groups. The greater the credibility and QM practices, the better the knowledge transferred. The literature does not show studies that have described this relationship explicitly. Most existing studies analyze TMS generally, and there is little theoretical and empirical evidence. Credibility and coordination in TMS are associated with trust in the reliability of others' knowledge (Chen and Leung, 2010). The 
more the members of the group trust and believe in each other, the more rapidly and effectively knowledge is transferred. We therefore propose the following hypothesis:

H2. QM practices moderate the effect of credibility and coordination within TMS as they relate to $\mathrm{KT}$ in $\mathrm{R} \& \mathrm{D}$ groups.

Specialization in TMS can be considered a facilitator of KA, since the system in itself has as its goal knowledge exchange, in which the process is initiated by someone who seeks specific knowledge and the knowledge provided by another person who has it. The members of the system differ in the experience, knowledge, and information that they provide to the group (Huang and Huang, 2007). According to the foregoing, KA from people specialized in a specific subject matter are important for achieving high levels of effectiveness in groups, which is strengthened through QM practices. What is important is who specializes in what in order to facilitate exchange of knowledge on the group level (Huang and Huang, 2007). Therefore, we propose the following hypothesis:

H3. QM practices moderate the effect of TMS specialization in their relationship to KA in R\&D groups.

Coordination and credibility supported by QM practices encourage knowledge absorption, because, the more integrated and coordinated the group, the more easily knowledge is absorbed. Thus, if credibility and coordination as well as QM practices are present, better absorption of knowledge will be achieved, increasing the group's shared memory. Some research has shown that TMS generally have positive effects on groups' performance (Moreland and Myaskovski, 2000; Wang and Farn, 2012) and that they facilitate the dissemination of tacit information (Akgün et al., 2006). Based on the foregoing, we believe that TMS linked to QM practices can facilitate knowledge absorption in R\&D groups. We thus propose the following hypothesis: 
H4. QM practices moderate the effect of credibility and coordination within TMS in their relationship to KA in $\mathrm{R} \& \mathrm{D}$ groups.

\section{Research design}

\subsection{Description of the data}

We created a database that included 12,434 Spanish university R\&D groups that had posted information on the Internet, according to the criteria of the Andalusian Regional Government. Spanish university $R \& D$ is composed of research groups located in different university faculties, research centres, laboratories, etc. These groups' fundamental goal is to perform research and transfer knowledge to society in general. The groups are usually composed of university professors, research assistants, and, in some cases, professionals in the sector. The groups are usually managed by university professors themselves. We selected a sample of 3000 groups through simple random sampling, composed of Spanish university R\&D groups that belong to all areas of knowledge, regardless of size, region, age of the group, or scientific area. Choosing a sample of firms located in a relatively homogeneous geographic, cultural, legal, and political area minimizes the impact of the variables that cannot be controlled in the empirical research (Alder, 1983). We contacted each group's director of research and received 260 responses. Two responses were rejected because they were incomplete and one because it was received after the deadline. We thus obtained 257 questionnaires, giving a response rate of $8.57 \%$ and a sampling error, taking an infinite population, of $6.1 \%$ with a confidence level of $95 \%$. The largest number of surveys was from R\&D groups belonging to the area of the humanities, which composed $21 \%$ of the sample; followed by economics, social sciences, and law with 18\%; bio-health sciences with $13 \%$; and physics, chemistry and mathematics, and health technology with $11 \%$, respectively. Next in order were the groups for natural resources and ecology with $10 \%$, agro-food with $7 \%$, information and communications technologies 
with $5 \%$, and production technologies with $4 \%$. Table 1 shows a description of the directors of the R\&D groups surveyed.

Insert Table 1

\subsection{Measurement}

The procedure used to gather the data consisted of sending an email questionnaire. All of the scales were accompanied by a seven-category Likert scale (1 disagree completely and 7 agree completely). We performed a pre-test with five heads of groups, which enabled us to correct errors that affected the comprehension of some items and the control variables. To avoid possible errors that could bias the research, we confirmed that there was no possible bias due to nonresponding $R \& D$ groups in the sample, as this could create a problem for extrapolating from the results of the sample analyzed to the general population. To confirm whether such bias might be present, we analyzed whether there were significant differences between the R\&D groups that responded first and those that responded at the end of the period. The underlying idea is that the groups that answer later tend to be more similar to those that do not respond.

The results obtained after performing the relevant statistical tests demonstrated the validity of the responses obtained, since there is no possibility of nonresponse bias (Armstrong and Overton, 1977) or common response bias (Podsakoff et al., 2003), which can arise in this kind of study. Following the methodology proposed by Armstrong and Overton (1977), we divided the sample into two groups: the first was composed of $74 \%$ of the groups, which were the first to respond, and the second of the remaining 26\%. The ANOVA demonstrated that there are no significant differences. 


\section{QM Practices}

To measure the QM practices, we adopted the scale developed by Prajogo and Sohal (2006), which was validated for Australian and Korean organizations in the R\&D sector. All of the Cronbach's alpha values for the scales were above 0.75 , demonstrating the reliability of the scale for this environment.

We also included teamwork, adapting the scale of Flynn et al. (1995) because it was adapted perfectly to the sector studied and because working in teams has advantages for performance in university R\&D. Thus, the measurement scale was composed of six variables: leadership, strategic planning, customer focus, information and analysis, human resource management, and teamwork.

\section{TMSS and TMSC}

To analyze TMS, we adapted the scale proposal by Akgün et al. (2005), which has also been used to measure the construct in R\&D groups in Taiwan (Huang, 2009). TMS were analyzed from two dimensions (Lewis, 2003): specialization (TMSS), and credibility and coordination (TMSC)

\section{Knowledge transfer}

For KT, we adapted the scale proposed in the study by Bock et al. (2005), which performed a field study with 154 managers to examine attitudes and subjective norms in relation to knowledge exchange.

\section{Knowledge absorption}

For KT, we decided to adapt the scale proposed by Szulanski (1996), due to the general acceptance of the scale and the ease of adapting it to the sector studied. Appendix B shows all of the scales, with the items from each that were used in the research. 


\section{The exploratory factor analysis}

To guarantee the scales' unidimensionality, we performed an exploratory factor analysis with the statistical program SPSS 15.0. This analysis is considered to be a technique for reducing the data. Unidimensionality is achieved if all of the items explain a single construct (Ahire, et al. (1996). The variable of teamwork was divided into two, since the statistical analyses showed that it was measuring more than one factor: flexible teamwork, which according to the literature review measures teamwork that accentuates the capacity for flexibility in the team; and strategic teamwork, which attempts to analyze the role of management in the group (see Table 2). As one can see from the matrix for the principal component analysis, the indicator measured more than one factor. We used the Varimax rotation method with Kaiser's Normalization.

Insert Table 2

Thus, all of the scales fulfil the requirements of unidimensionality, demonstrating that each indicator measured only one construct (see Table 3). The analysis of the scales' internal consistency shows a high Cronbach's alpha coefficient $(\alpha=0.7)$, an acceptable value according to the minimum recommended value of 0.7 (Nunnally, 1978).

Insert Table 3

\section{The confirmatory factor analysis}

The results of the confirmatory factor analysis show that all of the indicators fulfil the three requirements. These three requirements are: (a) all of the factor loadings are significant 
$(t>1.96 ; p<0.05)$, (b) greater than 0.5 , and (c) that the value for individual reliability $\left(\mathrm{R}^{2}\right)$ is above 50\% (Hulland, 1999) (see Table 4). Further, the Cronbach's alphas must be greater than 0.7 and the measurements of variance extracted greater than 0.5 (Nunnally, 1978) (see Table 3).

Insert Table 4

In the analysis, only one item was eliminated (TMSS2), maintaining nearly all of the content validity of the scales. The item eliminated belongs to specialization in transactive memory systems (TMSS). It did not have significant weight in the scale (0.292) and therefore affected the variance explained greatly $(48.046 \%)$. After we eliminated the item, the scale improved significantly, explaining $60.500 \%$ of the variance. In conclusion, all of the scales used can be considered to be reliable and valid. They fulfil all of the requirements for unidimensionality, reliability, and validity.

\section{Data analysis}

For the data analysis, we used the multiple linear regression technique with moderation effect, supported by the statistical program SPSS version 15.0. The moderating variable was QM practices, treated as a second-order latent variable measured through six first-order latent 
variables. We performed tests to determine whether the data were well suited, observing whether the expectations of linearity, normality, homoscedasticity, and multicollinearity were fulfilled (Hair et al., 2004). When interaction terms are used in the analysis, these terms are highly correlated, causing multicollinearity and unstable estimations (Hair et al., 2004). They thus focus on the direct terms, subtracting the mean of each variable from the values of each observation. Table 5 shows the descriptive analysis of the sample, as well as the correlation matrix (see Table 6).

\section{Insert Table 5}

Insert Table 6

In Table 7, which shows the results of the analyses, we see that problems of multicollinearity do not appear among the independent variables. The tolerance values (close to 1 , threshold set at $0-1$ ) and the variance inflation factor (VIF) (close to 1, threshold set at 10) are found to be within the appropriate levels. It is necessary to ensure that the tolerance is not greater than the degree to which each independent variable is explained by other independent variables, and the VIF is the inverse of the tolerance (Hair et al., 2004).

\section{Insert Table 7}

\subsection{Multiple regression analysis with moderating effect}

Using the statistical program SPSS version 15.0, we investigated the moderating effect that QM practices can have on the relationship between QM and the facilitating elements (TMSS and TMSC) and knowledge absorption and transfer. We proposed a total of four regression models, accompanied by the control variables, as these are the variables that ensure that the changes in the independent variable are not those that explain or cause changes in the dependent variable. We used the number of members and income of the group, which were not shown to be significant, making the results valid for any Spanish university R\&D group, 
regardless of its number of members or income level. These two control variables, along with others, have been used in studies related to R\&D (Filatotchev, et al., 2003; Hoegl and Praveen, 2006; Muethel, 2012). Due to the importance of the size of the groups and of the group's budget to the intensity of the R\&D, we have used the variable of size in our study.

The control variables used enable us to extrapolate from the results to any university $R \& D$ group, regardless of the group's size or income level. This control variables could affect other variables and that, if not taken properly into account, may change the results due to bias.

Table 8 shows the regression analyses performed, from which we see that introducing the interaction element causes a significant increase in the $\mathrm{R}^{2}$ values for the cases in which the dependent variable was KT. When we introduce the moderating effect (TMSS X QM), the increase is 0.032 , giving a confidence level of $99 \%$, which explains $19.4 \%$ of the independent variable. Thus, the total effect of TMSS on KT increases positively with the introduction of the interaction element, which is found to be represented by both the linear effect and the moderating effect $(0.072+0.112 \times \mathrm{QM})$. The relationship between TMSC and KT behaved the same way in the presence of $\mathrm{QM}$ practices. The value of $\mathrm{R}^{2}$ increased from $26.8 \%$ to $34.9 \%$, explaining a greater percentage of the KT when the interaction element was included and thus represented by both effects: linear and moderating $(0.258+0.162 \times \mathrm{QM})$. The independent variables explain a greater variance of KT when we include the moderating effect of QM practices on the relationships studied. This result supports the hypotheses analyzed that refer to the moderating effect of QM practices on the relationship of specialization and credibility and coordination to KT. We therefore accept research hypotheses 1 and 2.

Insert Table 8 
Table 9 shows the estimation of the regression model of QM practices as a variable moderating the relation of TMSS and TMSC to KA. We see in both cases that introducing the moderating element in the equations does not cause a change in the value of $\mathrm{R}^{2}$, indicating that the influence of the moderating effects TMSS X QM and TMSC X QM is not significant for the relationships studied. Consequently, hypotheses 3 and 4 are not supported.

Insert Table 9

\section{Discussion and future lines of research}

In this study, we have investigated the relationship of specialization within TMS and credibility and coordination within the TMS itself to knowledge transfer and absorption, using QM practices as a moderating variable. We analyzed a total of four relationships, of which two are supported and two are not. Based on the existing literature on this topic, we identified six QM practices, which were treated as a second-order variable. We believe that these practices strengthen the creation of dynamic capacities in the sector studied when analyzed from both the theoretical and the empirical point of view. This investigation is the first to study the moderating effect of QM practices on the relationships proposed, and our results contribute to filling this theoretical gap.

The relationships corresponding to $\mathrm{KT}$ and specialization as well as credibility and coordination in the TMS were found to be significant when we introduced QM practices as a moderating variable, but this was not the case for KA. These results lead us to think that, even though QM practices with all of their known benefits were implemented, the elements mentioned above did not encourage KA. Such results make important contributions to our understanding of the constructs of knowledge transfer and absorption and of TMS. Our study also provides information on the use of these moderating variables to strengthen the explanation of relationships between the variables in the field of economics, supporting other 
studies in this field that have obtained positive results (Oltra and Flor, 2010; Prajogo, 2011). This research thus proposes that QM practices constitute one of the variables Strategic influencing KT positively in university $\mathrm{R} \& \mathrm{D}$ when it is combined with the two facilitating elements analyzed.

As proposed above, the connection of TMS to QM practices did not have an effect on the relationships tested. We believe that this result is due to the highly specific characteristics of the sector, in which other factors beyond working in a quality environment are necessary for achieving good KA, such as sufficient preparation to enable identification of relevant knowledge (Reagans and McEvily, 2003; Volberda et al., 2010) and the personal intention and desire to absorb knowledge. This result may also be due to the fact that KA is a routine daily task in the university $R \& D$ sector and must be performed, whether or not one works in a quality environment. Because TMS refer to the cooperative division of labour (Hollingshead, 2001), we may attribute our results to the fact that university R\&D groups develop various research projects simultaneously. In this case, each group focuses on its own research, a situation that does not encourage the creation of a work team framed by a single project and that may slow knowledge absorption. It would therefore be ideal to have a stable team involved in the development of a single project in which tasks and responsibilities are distributed among the members. This would enable specialization in different roles and domains of knowledge (Brandon and Hollingshead, 2004), encouraging absorption.

Further, the survey was addressed to area managers, who gave their opinion on how they perceive these issues. Volberda et al. (2010) propose that managers perceive issues through their own cognitive goals, not considering the environment as a source of valuable knowledge to be absorbed. Thus, another factor that may have influenced the results is the different internal mechanisms that university R\&D groups have, such as structure (Van den Bosch et al., 1999), rotation of positions, connectivity, and socialization techniques (Jansen et al., 2005), as well as the age of the group. Messeni (2011) argues that the existence of prior links 
contributes to increasing the exchange of knowledge in groups. Therefore, it seems that there are other variables, whether mediating or moderating, that led to an outcome in which the relationship of these elements to knowledge absorption was not significant. The effect of these variables might strengthen the relationship positively. In fact, there is an effect of the relationship between the TQM and knowledge absorption. In the correlation matrix, one can see that the construct shows a good correlation with individual quality practices. However, we do not find that knowledge absorption is encouraged when analyzed in a quality environment, that is, when we study all of the quality management practices as a whole, connected to TMS. This is not the case for KT, which does require stimulation of the benefits of QM. Knowledge transfer benefits directly from quality management practices and TMS. However, when we introduce the interaction, the percentage of the variable explained increases. By performing a general analysis, we can propose that both dependent variables-knowledge transfer and knowledge absorption- benefit directly from TMS and TQM. The problem occurs when we introduce the interaction. It would thus be interesting to study other practices that could improve the interaction in order to achieve an improvement in the entire process of knowledge transfer and absorption so important for R\&D in general.

The connection of KT to TMS in its two dimensions was significant in the presence of QM practices. This result is due to the fact that QM encourages the integration of teams, fostering credibility, coordination, and specialization within the team. As a result, one obtains a greater quantity of information than in teams whose members work separately (Moreland and Myaskovsky, 2000). Further, knowledge is used to improve access to the competencies required at each moment and to coordinate actions (Sánchez et al., 2006). This interpersonal consciousness of the ability and specialization of others promotes both behaviour that searches actively for information and analysis among the members of the team, improving KT by performing tasks collectively (Austin, 2003).

Human resource management enables teams that learn together to complete a task and to develop differentiated knowledge inherent in TMS. The process is initiated by someone who seeks specific knowledge, and that knowledge is provided by another person who has it 
(Huang and Huang, 2007). Leadership helps to demonstrate that teams are a distributed knowledge system (Yoo and Kanawattanachai, 2001), in which people pool their efforts and focus on goals guided by the right strategic planning. Further, teamwork enables the distribution of tasks and responsibilities, encouraging specialization in different roles and domains of knowledge (Brandon and Hollingshead, 2004). Focus on the customer is one of the dimensions that influence employees' tasks (Pei-Lee et al., 2009). Therefore, Chatterji and Davidson (2001) propose that QM helps R\&D to focus on the customer's needs and expectations.

The significant relationship of the variables analyzed may be due to the explanation proposed by Satyendra and Harsh (2011), who suggest that applying QM in R\&D is one way for organizations to improve, because the members gain in identity, facilitating knowledge exchange (Bryant, 2003). We therefore propose that R\&D groups that develop TMS and are supported by QM environments will be better able to develop KT capacity. These results show the positive effects of QM practices and add to the group of studies that argue along these lines. The results also strengthen a vital dynamic capacity for the sector analyzed, that is, $\mathrm{KT}$.

This study thus shows that, although QM is used more in the business sector, it has applicability in non-business organizations. Further, we propose that the literature that analyzes the elements encouraging the creation of dynamic capacities is currently scattered and minimal. Our results contribute information to filling this gap by demonstrating empirically that TMS is a facilitator of KT in the sector studied and that is it strengthened by QM.

The theoretical implications of this study address gaps in the existing research, since the relationships studied to date have been analyzed in isolation. Further, studies of R\&D are scarce, and we find no such studies of university R\&D. Our research also contributes to the 
study of moderating effects and opens new analytical perspectives for university $R \& D$, as it provides information not studied in the sector.

From the practical point of view, the results constitute a working tool for managers in the sector, since they permit the use of QM to perfect their KT process. Further, we analyze group variables that are very important for the development of the group (TMS). The results will thus enable managers in the sector to increase their level of knowledge on how to manage university R\&D groups using a quality management focus. The research model proposed can help to create a change in the groups in which it is implemented. It will enable the use of quality management as a philosophy to perfect their management process, since the groups will develop knowledge transfer even more, and this attribute will help them to increase their levels of competitiveness and improve their R\&D cycle. In contrast, absorbing knowledge in the sector studied must be seen as a daily work routine that must be performed whether or not one is working in an environment of quality. This is not the case for knowledge transfer, which is necessary to stimulate the benefits of TQM. Further, this study serves as a reference for performing group analyses, showing quality management practices as a tool for improvement such study. It introduces both managers and researchers to recognizing the use of the managerial techniques studied here. Further, it helps managers in the sector to raise their level of knowledge about how to manage university R\&D groups using a quality management focus.

Replication of the model in other sectors and countries is possible and would be very interesting. The analysis of other groups would enrich our results, giving them a more totalizing and generalizable character. However, the R\&D sector has its own peculiaritiesfor example, its knowledge-based processes facilitate the application of the model. Thus, the specific characteristics of the R\&D sector do not enable us to affirm that one can apply the model to other sectors with the same results. Such application could be undertaken in future lines of research. 
The limitations of this study lie in the cross-sectional character of the research and in the sample, which is composed of various sectors of knowledge that are not distributed equally. Further, we studied only Spanish groups; the results might differ if applied in another environment. Future research could analyze the individual moderating effect of each QM practice to determine its contribution to strengthening the relationships studied. Research by area of knowledge would also be interesting, and other key quality management practices could be considered.

R\&D groups that develop the antecedent analyzed (TMS) and that are supported by QM environments will improve their ability to develop their knowledge transfer capacity, since they will see the functions of $R \& D$ as a process surrounded by the application of the principles and practices of continuous improvement. This study demonstrates the generic character of QM practices that permits their adaptability to any environment. R\&D groups that develop QM practices can stimulate the capacity for knowledge transfer supported in TMS as a facilitating element better than those research groups that do not work in a QM environment. In the literature, no studies described have tested this effect empirically, and our study contributes information to fill this gap, while also providing information on the use of QM practices in R\&D in Spanish universities.

\section{REFERENCES}

Akgün, A.E., Byrne, J.C., Keskin, H. and Lynn, G.S. (2006), “Transactive memory system in new product development teams", IEEE Transactions on Engineering Management, Vol.53, No.1, pp.95-111.

Akgün, A.E., Byrne, J.C., Keskin, H., Lynn, G.S. and Imamoglu, S.Z. (2005), "Knowledge network in new product development project: A transactive memory perspective", Information and System, Vol.42, No.8, pp.1105-1120.

Alavi, M. and Tiwana, A. (2002), "Knowledge integration in virtual teams: The potential role of KMS”, Journal of the American Society for Information Science and Technology, Vol.53, No.12, pp.1029-1037. 
Alder, N.J. 1983, “A typology of management studies involving culture”, Journal of International Business Studies, Vol. 14, No.2, pp. 29-47.Antony, J. (2000), “Ten key ingredients for making SPC successful in organisations”, Measuring Business Excellence, Vol.4, No.4, pp.7-10.

Argote, L. and Ingram, P. (2000), "Knowledge transfer: A basis for competitive advantage in firms", Organizational Behavior and Human Decision Processes, Vol.82, No.1, pp.150-169.

Armstrong, J.S. and Overton T.S. (1977), "Estimating nonresponse bias in mail surveys", Journal of Marketing Research, Vol.14, No.3, pp. 396-402.

Austin, J.R. (2003), "Transactive memory in organizational groups: The effects of content, consensus, specialization and accuracy on group performance", Journal of Applied Psychology, Vol.88, No.5, pp.866878.

Bock, G.W., Zmud, R.W. and Kim, Y.G. (2005), "Behavioral intention formation in knowledge sharing: examining the roles of extrinsic motivators, social-psychological forces, and organizational climate", MIS Quarterly, Vol.29, No.1, pp.87-111.

Boon, C., Boselie, P., Paauwe, J. and Denhartog, D.N. (2007), "Measuring strategic and internal fit in HRM: An alternative approach", Paper presented at the Annual Academy of Management meeting, Conference Proceedings, August 2007, Philadelphia. pp.1.

Brandon, D.P. and Hollingshead, A. (2004), "Transactive memory systems in organizations: Matching tasks, expertise and people”, Organization Science, Vol.15, No.6, pp.633-644.

Bryant, E. (2003), "The role of transformational and transactional leadership in creating, sharing and exploiting organizational knowledge”, Journal of Leadership and Organizational Studies, Vol.9, No.4, pp.32-44.

Chatterji, D. and Davidson, J.M. (2001), "Examining TQM's legacies for R\&D", Research Technology Management, Vol.44, No.1, pp.10-12.

Chen, Z. and Leung, K. (2010), "The effect of team conflict and task type on team knowledge sharing through transactive memory system", Information Management and Engineering (ICIME), The 2nd IEEE International Conference, 16-18 April 2010, pp.492-496.

Dean, J. and Bowen, D. (1994), "Management theory and total quality: improving research and practice through theory development", Academy of Management Review, Vol.19, No. 3, pp.392-418. Faraj, S. and Sproull, L. (2000), "Coordinating expertise in software development teams", Management Science, Vol.46, No.12, pp.1554-1568.

Filatotchev, I. , Piga, C. and Dyomin, N. (2003). "Network positioning and R\&D activity: a study of Italian groups". R\&D Management, Vol. 33, No. 1, pp.37-48. 
Flynn, B.B., Schroeder, R.G. and Sakakibara, S. (1995), "The impact of quality management practices on performance and competitive advantage”, Decision Sciences, Vol.26, No.5, pp.659-691.

Ghosh, S., Handfield, R.B., Kannan, V.R. and Tan, K.CH. (2003), “A structural model analysis of the Malcolm Baldridge National Quality Award framework", International Journal of Management and Decision Making, Vol.4, No.4, pp.289-311.

Grant, R.M. (1996), "Prospering in dynamically-competitive environments: Organizational capability as knowledge integration”, Organization Science, Vol.7, No.4, pp.375-387.

Grover, S., Agrawal, V.P. and Khan, I.A. (2006), "Role of human factors in TQM: A graph theoretic approach", Benchmarking: An International Journal, Vol.13, No.4, pp.447-468.

Gutiérrez, G.L.J., Torres, I.T. and Molina, V.B. (2010), "Quality management initiatives in Europe: An empirical analysis according to their structural elements", Total Quality Management and Business Excellence, Vol.21, No.6, pp.577-601.

Hair, H.F., Anderson, R.E., Tatham, R.L. and Black, W.C. (2004): “Análisis multivariante”, Ed: Prentice Hall, Madrid.

Hamid, A., Aziati, N. and Juhana S. (2011), “A conceptual framework of knowledge transfer in Malaysia EGovernment IT outsourcing: An integration with Transactive Memory System (TMS)”, International Journal of Computer Science, Vol.8, No.5, pp. 51-64.

Heras, S.I., Casadesus, M. and Marimon, F. (2011), “The impact of ISO 9001 standard and the EFQM model: The view of the assessors", Total Quality Management, Vol.22, No.2, pp.197-218.

Hirtz, P.D., Murray, S.L. and Riordan, C.A. (2007), "The effects of leadership on quality", Engineering Management Journal, Vol.19, No.1, pp.22-27.

Hoegl, M. and Praveen, K.P. ( 2006), "Team reflexivity in innovative projects". R\&D Management, Vol.36, No.2, pp.113-125.

Hollingshead, A.B. (2001), "Cognitive interdependence and convergent expectations in transactive memory”, Journal of Personality and Social Psychology, Vol.81, No.6, pp.1080-1089.

Huang, C.C. and Huang, T.J. (2007), "Knowledge Sharing and KM Effectiveness in Technology R\&D Teams: Transactive Memory System and Team-based Outcome Expectations Perspectives", in Industrial Engineering and Engineering Management 2007 IEEE International Conference Proceedings of the 2007, IEEE IEEM, 2-4 Dec., pp.2124-2128.

Huang, CH. (2009), "Knowledge sharing and group cohesiveness on performance: An empirical study of technology R\&D teams in Taiwan", Technovation, Vol.2, No.11, pp.786-797. 
Hulland, J. (1999), “Organizational learning: the contributing processes and the literatures", Organization Science, Vol.2, No.1, pp.119-126.

Husted, K. and Michailova, S. (2002), "Diagnosing and fighting knowledge sharing hostility”, Organizational Dynamics, Vol.31, No.1, pp.60-73.

Jackson, P. (2011), "Requirements for an information system to support transactive memory", The Journal of Information and Knowledge Management Systems", Vol.41, No.4, pp.401-427.

Jackson, P. and Klobas, J. (2008), “Transactive memory systems in organization: Implications for knowledge directories", Decision Support Systems, Vol.44, No.2, pp.409-424.

Jansen, J., Van Den Bosch, F. and Volberda, H. (2005), "Managing potential and realized absorptive capacity: How do organizational antecedents matter?”, Academy of Management Journal, Vol.48, No.6, pp. 9991015 .

Jiménez, J.D. and Martínez C.M. (2009), “The performance effect of HRM and TQM: A study in Spanish organizations", International Journal of Operations \& Production Management, Vol.29, No.12, pp.12661289.

Kiella, M.L. and Golhar, D.Y. (1997), “Total quality management in an R\&D environment”, International Journal of Operations \& Productions Management, Vol.17, No.2, pp.184-198.

Kumar, V. and Boyle, T. (2001), “A quality management implementation framework for manufacturing-based R\&D environments”, International Journal of Quality and Reliability Management, Vol.18, No.3, pp.336359.

Lakshman, C. (2006), “A theory of leadership for quality: Lessons from TQM for leadership”, Total Quality Management, Vol.17, No.1, pp.41-60.

Lewis, K. (2003), "Measuring transactive memory systems in the field: Scale development and validation", The Journal of Applied Psychology, Vol.88, No.4, pp.587-604.

Lewis, K. (2004): “Knowledge and performance in knowledge-worker teams: A longitudinal study of transactive memory systems", Management Science, Vol.50, No.11, pp.1519-33.

Messeni, A.P. (2011), "The impact of technological relatedness, prior ties, and geographical distance on university-industry collaborations: A joint-patent analysis”, Technovation, Vol.31, No.7, pp.309-319.

Moreland, R.L. and Myaskovsky, L. (2000), "Exploring the performance benefits of group training: Transactive memory or improved communication?", Organizational Behavior and Human Decision Processes, Vol.82, No.1, pp.117-133.

Muethel, M., Siebdrat, F. and Hoegl, M. (2012), "When do we really need interpersonal trust in globally dispersed new product development teams?", $R \& D$ Management, Vol.42, No.1, pp.31-46. 
Nunnally, J.C. (1978), “Psychometric theory”, McGraw Hill, New York.

Oltra, M.J. and Flor, M.L. (2010), “The moderating effect of business strategy on the relationship between operations strategy and firms' results", International Journal of Operations \& Production Management, Vol.30, No.6, pp.612-638.

Pearson, A.W., Vaughan, N. and Butler, J. (1998), “The implementation of TQM in R\&D”, International Journal of Technology Management, Vol.16, No.4/6, pp.405-432.

Pei-Lee, T., Chen-Chen, Y., Veeri, A. and Keng-Boon O. (2009) "Does total quality management reduce employees’ role conflict?”, Industrial Management \& Data Systems, Vol.109, No.8, pp.1118-1136.

Podsakoff, P.M. and Organ, D.W. (1986), "Self-reports in organizational research: Problems and prospects", Journal of Management, Vol.12, No.4, pp.531-544.

Prajogo, D.I. (2011), “The roles of firms' motives in affecting the outcomes of ISO 9000 adoption", International Journal of Operations \& Production Management, Vol.31, No.1, pp.78-100.

Prajogo, D.I. and Hong, S.W. (2008), “The effect of TQM on performance in R\&D environments: A perspective from South Korean firms", Technovation, Vol.28, No.12, pp.855-863.

Prajogo, D.I. and Sohal, A.S. (2001), “TQM and innovation: A literature review and research framework", Technovation, Vol.21, No.8, pp.539-558.

Prajogo, D.I. and Sohal, A.S. (2006), “The integration of TQM and technology and R\&D management in determining organizational performance: An Australian perspective”, Omega, Vol.34, No.3, pp.296-312.

Price, R.C. (1995), “TQM in the R\&D function”, Quality Progress, Vol.28, No.7, pp.109-111.

Reagans, R. and McEvily, B. (2003), "Network structure and knowledge transfer: The effects of cohesion and range”, Administrative Science Quarterly, Vol.48, No.2, pp.240-267.

Sánchez, M.M., Rico, R., Gil, F. and San Martín, A. (2006), "Nuevas formas de liderazgo en equipos de trabajo", Papeles del psicólogo", Vol.32, No.1, pp.38-47.

Satyendra, K. and Harsh, M. (2011), “Total quality management: An ethical research and development based study and scenario", International Journal on Science and Technology, Vol.2, No.1, pp.44-48.

Sharma, M. and Ghosh, A. (2007), "Does team size matter? A study of the impact of team size on the transactive memory system and performance of IT sector teams", South Asian Journal of Management, Vol.14, No.4 pp.96-115.

Silá, I. and Ebrahimpour, M. (2005), “Critical linkages among TQM factors and business results”, International Journal of Operations \& Production Management, Vol.25, No.11, pp.1123-1155.

Szulanski, G. (1996), "Exploring internal stickiness: impediments to the transfer of best practice within the firm”, Strategic Management Journal, Vol.17, No.Winter special, pp.27-43. 
Tarawneh, A. and Ahmad, H. (2010), “Total Quality Management and leadership an experimental investigation of ISO certified companies in Jordan”, Interdisciplinary Journal of Contemporary Research in Business, Vol.2, No.1.

Van den Bosch, F.A.J., Volberda, H.W. and De Boer, M. (1999), “Coevolution of firm absorptive capacity and knowledge environment: Organizational forms and combinative capabilities", Organization Science, Vol.10, No.5, pp.551-568.Volberda, H.W., Foss, N. and Lyles, M.A. (2010), “Absorbing the concept of absorptive capacity: How to realize its potential in the organization field", Organization Science, Vol.21, No.4, pp.121.

Wang, Ch. and Farn, Ch.K. (2012), "Explore the knowledge integration in knowledge teams from a transactive memory perspective”, 2012 45th International Conference on System Sciences. 2012 IEEE, Hawaii.

Wegner, D. M. (1986), “Transactive memory: A contemporary analysis of the group mind”. In B. Mullen and G. R. Goethals (Eds.), Theories of group behavior, New York. Springer-Verlag. pp.185-208.

Yoo, Y. and Kanawattanachai, P. (2001), "Developments of transactive memory systems and collective mind in virtual teams", International Journal of Organizational Analysis, Vol.9, No.2, pp.187-208.

Zahra, S. and George, G. (2002), “Absorptive capacity: A review, reconceptualization, and extension”, Academy of Management Review, Vol.27, No.2, pp.185-203. 